RAND RESEARCH AREAS CHILDREN AND FAMILIES EDUCATION AND THE ARTS ENERGY AND ENVIRONMENT HEALTH AND HEALTH CARE INFRASTRUCTURE AND TRANSPORTATION INTERNATIONAL AFFAIRS LAW AND BUSINESS NATIONAL SECURITY POPULATION AND AGING PUBLIC SAFETY SCIENCE AND TECHNOLOGY TERRORISM AND HOMELAND SECURITY
This product is part of the RAND Corporation research brief series. RAND research briefs present policy-oriented summaries of published, peer-reviewed documents.

Corporate Headquarters 1776 Main Street P.O. Box 2138 Santa Monica, California 90407-2138 TEL 310.393 .0411 FAX 310.393 .4818 (c) RAND 2011

\title{
What Are the Public Health Implications of Prisoner Reentry in California?
}

$\mathrm{T}$ he landscape for assessing the public health implications of prisoner reentry in California has changed dramatically over the past few years. First, California (and the nation as a whole) is in the midst of a deep and persistent recession, which has significantly weakened the health care safety net that ex-prisoners rely on. Second, California's new 2011 Public Safety Realignment Plan—which shifts responsibility for low-level offenders away from the state and on to counties-will have a number of implications for thinking about meeting the health care and rehabilitative needs of the reentry population. Finally, implementation of the federal Patient Protection and Affordable Care Act (ACA) will expand Medicaid eligibility and, thus, will help in removing a key barrier to access to care for the reentry population.

This puts California at an important crossroads: The state faces numerous challenges, but the recent changes in policy also present important opportunities to improve California's ability to meet the needs of individuals returning from state prison. In this context, then, it is critical to better understand the public health issues associated with returning ex-prisoners, to help communities and providers in the communities to which ex-prisoners return better meet the reentry and health care needs of this population.

This study helps inform planning for these policy changes by producing a "state-of-the-state" report - a synthesis of findings from a multiyear effort- that examines the specific health care

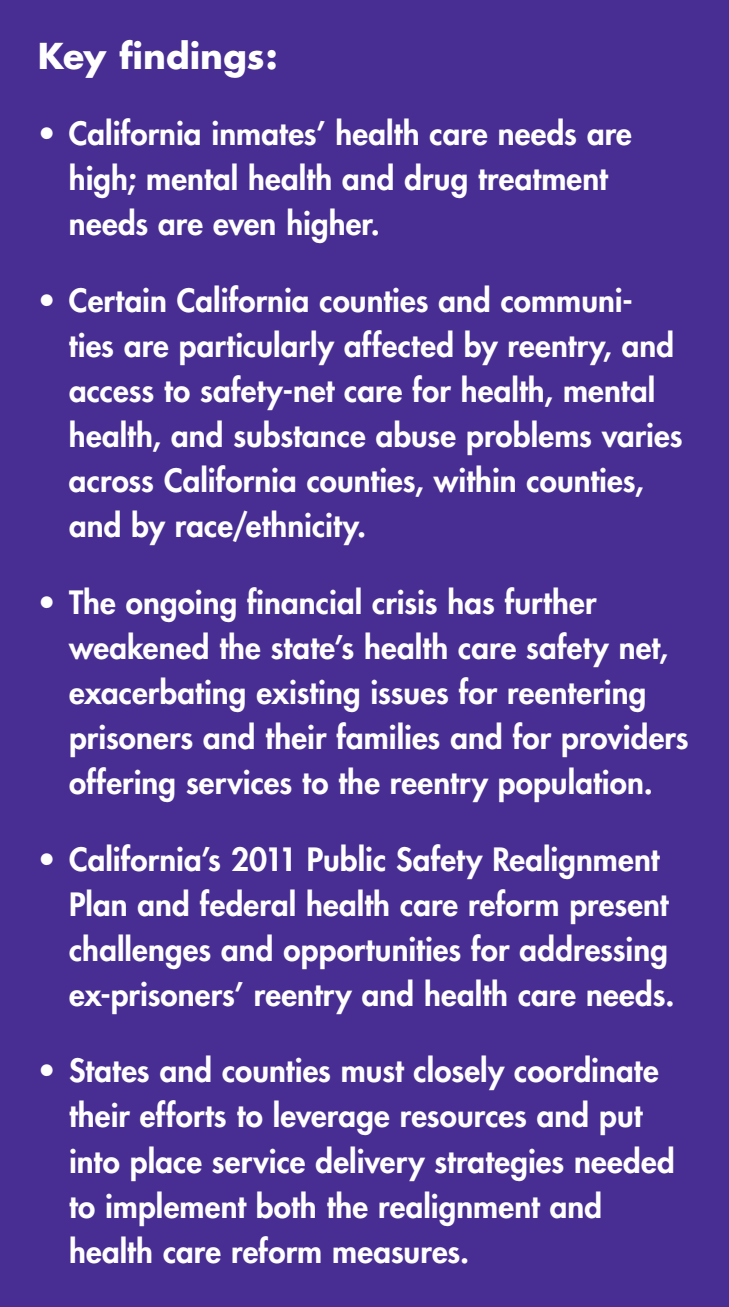

needs of California's reentry population, the public health challenges of reentry in California, and the policy options for improving access to

\section{This research highlight summarizes RAND research reported in the following publication:}

Davis LM, Williams MV, DeRose KP, Steinberg P, Nicosia N, Overton A, Miyashiro L, Turner S, Fain T, and Williams E III, Understanding the Public Health Implications of Prisoner Reentry in California: State-of-the-State Report, Santa Monica, Calif.: RAND Corporation, MG-1165-TCE, 2011 (http://www.rand.org/pubs/monographs/MG1165.html). 
health care safety-net resources for this population within the context of significant policy changes.

\section{What Are Inmates' Health Care Needs?}

Based on an analysis of self-reported data from California inmates in the Bureau of Justice Statistics (BJS) Survey of Inmates in State and Federal Correctional Facilities, we found that California inmate health care needs are high. In particular, inmates self-report a high burden of chronic diseases, such as asthma and hypertension, and infectious diseases, such as hepatitis and tuberculosis—conditions that require regular health care for effective management. Among those who reported a current medical issue, most reported seeing a physician since admission to prison; but their likelihood of receiving health care upon release is lessened by barriers to accessing care and obtaining health insurance. Thus, ex-prisoners returning to communities bring a host of unmet health needs and will depend on counties' abilities to meet those needs.

Our analysis shows that self-reported mental health and drug treatment needs are especially high. About twothirds of California inmates reported having a drug abuse or dependence problem. Yet among those reporting drug abuse or dependence, only 22 percent reported receiving treatment since admission to prison. More than half of California inmates reported a recent mental health problem, with about half of those reporting receiving treatment in prison. Given the high prevalence of these problems in the prison populationand that most prisoners do not receive care for these problems in prison-ex-prisoners' need for services in communities is likely to be particularly high.

\section{What Challenges Do Providers Face in Meeting These Needs?}

To determine how such treatment needs place demands on or affect communities where inmates return, we reviewed the relevant literature about ex-prisoners' access to insurance and how the safety net is organized to meet ex-prisoners' needs. In parallel, we conducted exploratory interviews with a group of health care providers in clinics, community health centers, drug treatment programs, and multiservice centers in Alameda, Los Angeles, and San Diego counties. Although our sample of providers does not cover the full range of provider perspectives, the themes and stories we heard are consistent with what the literature says and with what we heard in focus groups with ex-prisoners and family members of prisoners in the same three counties.

The interviews revealed that providers face a host of significant issues in treating this population:

- The reentry population has substantial treatment needs and is resource-intensive to treat. As reflected in the survey analysis and focus groups we conducted with ex-prisoners, providers note that this population has substantial mental health and substance abuse treatment needs, as well as significant health problems-needs exacerbated by neglect or reduced access to care. Also, this population has such non-health care needs as transportation, employment, housing, and family reunification. Given this complex set of needs and the prevalence of untreated health conditions, ex-prisoners tend to be more resourceintensive for providers to treat.

- Discharge planning is limited, raising concerns about continuity of care. Lack of medical records was seen as problematic, because providers must treat individuals without information about their past health status and care. For individuals with infectious diseases, such as HIV/AIDS or hepatitis, providers felt it was critical to know what kind of care and education a patient had received while incarcerated. This was also true for those with chronic health and mental health conditions. Providers also noted delays in seeking care upon release, leaving ex-prisoners at risk of running out of medications and self-medicating as a result.

- A number of factors limit access to care. Lack of health insurance or funding is a major barrier to accessing care, limiting the treatment options that providers and case managers have in referring individuals to services. For example, case managers can refer ex-prisoners to mental health counseling or drug treatment clinics that provide services on a sliding fee scale, but even this may be too expensive for these individuals without health insurance, who simply lack the ability to pay anything.

Also, individuals often have difficulties navigating the health care system, and the different silos in the health care and social services systems can complicate the referral process for those with a complex set of needs. Having patient navigators who are culturally competent and understand the experience of incarceration was seen as essential in helping the formerly incarcerated to link to services.

- Budget cuts have impacted providers. Providers reported on having to eliminate programs, such as HIV or dental programs, or to cut back on services, such as mental health programs. For example, a provider from a community assessment center noted the need to reassess whether to focus only on conducting assessments or to continue to also provide other services, such as drug treatment and mental health care. For one provider, state-level cuts in community-based treatment programs meant eliminating its sober living facility. Importantly, budget cuts also affected alcohol and drug treatment program models, including decreasing the length of stay in residential treatment programs. 


\section{What Counties and Communities Are Particularly Affected by Reentry?}

To understand which counties and communities individuals return to upon release, we conducted a geographic analysis using geocoded data for parolees released in 2005-2006 from California state prisons and a cluster analysis to examine the geographic distribution of parolees and identify concentrations of parolees across and within counties.

Figure 1 shows the clustering of parolees within California. The yellow circles identify clusters of parolees statewide; the black dots represent the count of parolees. The blue shading shows the concentration of parolees statewide, with darker shades of blue indicating those areas with higher parolee rates of return and lighter shades indicating those with lower rates of return. We found that certain counties have higher rates of return, and parolees tend to cluster in certain communities and neighborhoods within counties, which has implications for effectively targeting reentry and health care resources for this population. Eleven counties had the highest parolee rates, concentrated around the Bay Area and in the southern part of the state. By far the highest

\section{Figure 1}

Distribution of Parolees Across California

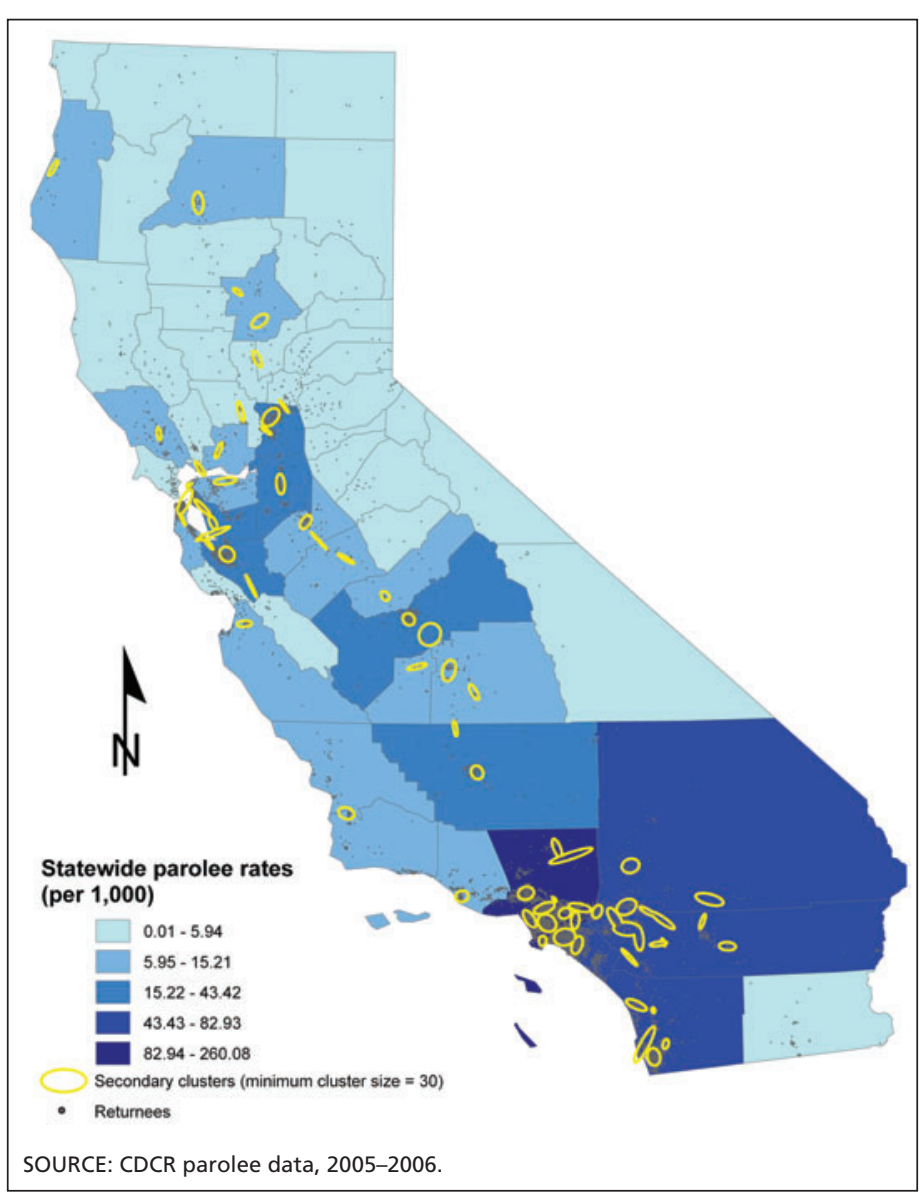

rates of parolee returns were in southern California, especially, Los Angeles, Orange, San Bernardino, Riverside, and San Diego counties. Looking within counties on the map, we find that most of the clusters are in urban areas, for example, near San Francisco, Oakland, the city of Los Angeles, and the city of San Diego.

Within the state, we focused on four counties that received one-third of the total parolees: Alameda, Kern, Los Angeles, and San Diego. For each county, we analyzed the distribution of parolees who returned to the individual counties. For example, almost 45 percent of the returning parolee population within Alameda County is concentrated in five distinct clusters of parolees primarily around Oakland and the northern section of the county. Kern County has four distinct clusters of parolees - two around the urban area of Bakersfield and two in the northern and northeastern sections of the county; these clusters accounted for almost 58 percent of parolees within Kern County. Eight clusters account for nearly half the parolee population within San Diego County, with the largest clusters near Downtown San Diego and Southeast San Diego. Finally, there are 23 distinct clusters of parolees covering a large geographic area but accounting for only 35 percent of the total number of parolees within Los Angeles County. This dispersion suggests that providing services to the reentry population requires a targeted approach in different county supervisorial districts and across urban and rural areas.

Analysis also shows that in California, African-American and Latino parolees, in particular, tend to return to disadvantaged neighborhoods and communities, defined by high poverty rates, high unemployment rates, and low educational attainment. Further, our analysis of the geographic distribution of safety-net resources, as discussed below, highlights that health care resources in these communities tend to be scarce.

\section{What Is the Capacity of the Health Care Safety Net to Meet Ex-Prisoners' Needs, and How Does It Vary?}

To assess the capacity of the health care safety net in the four counties, we assumed that most individuals returning from prison would become part of the medically indigent and uninsured population. Using facility data to characterize the respective health care, mental health, and substance abuse treatment safety nets in the four counties, we found that parolees' access to safety-net resources varies by facility type, by geographic area (across counties and within county), and by race/ ethnicity. As policymakers consider how to ensure access to services for the reentry population in California, they will need to take into account this variation in counties' safety nets.

For example, in Los Angeles County (as shown in Figure 2), some county supervisorial districts with high 
Figure 2

Gap Between Parolee Concentrations and Health Care Resources: Example of Southern Los Angeles County

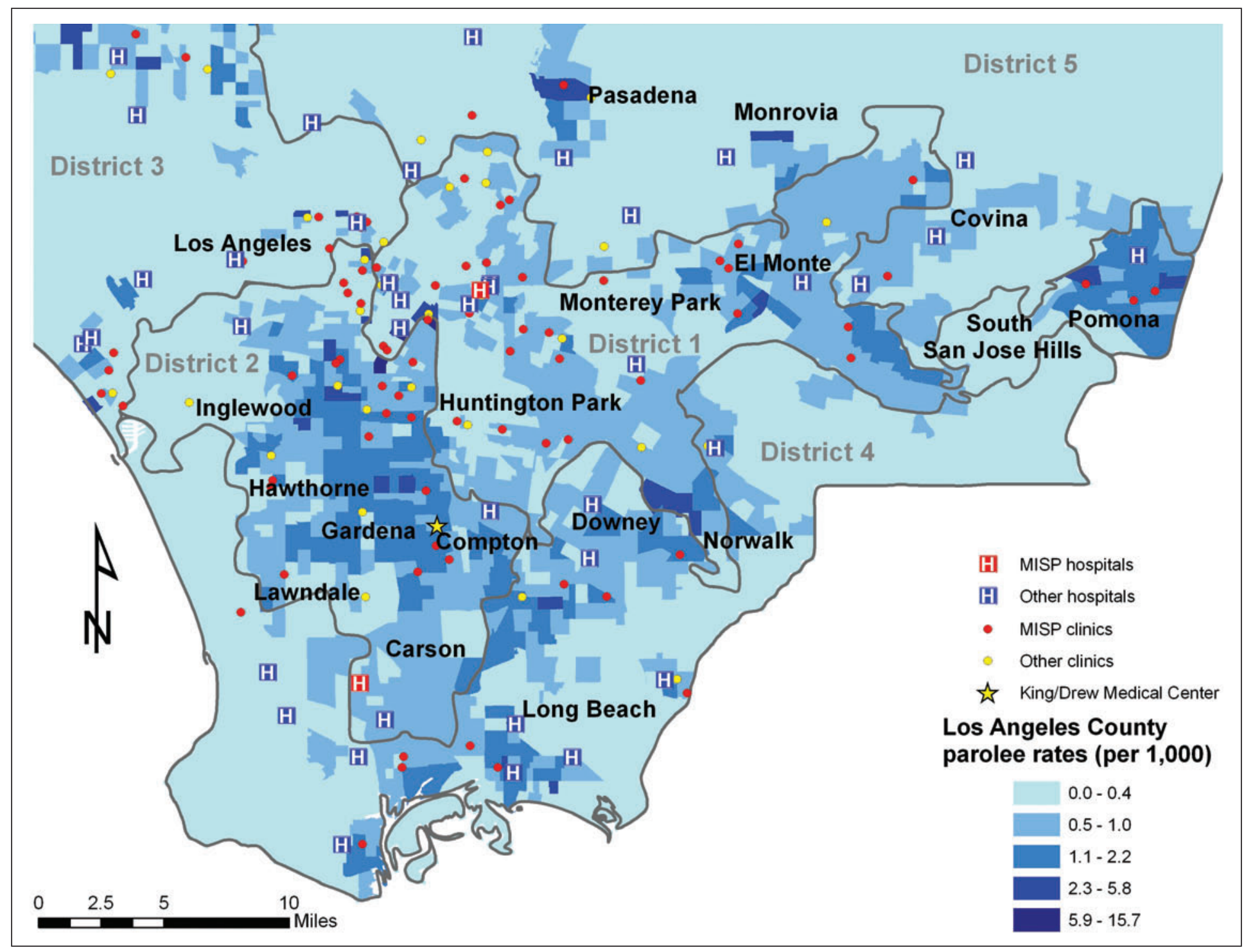

concentrations of parolees (the darker shades of blue) tend to have fewer hospital and primary care clinic resources. For instance, in District 2, which covers South Los Angeles and has relatively high concentrations of parolees, there is only one medically indigent service provider (MISP) hospital. There are also relatively sparse clinic resources, both MISP clinics and other primary care clinics, in this district. In all the counties, community clinics appear to play an important role in filling gaps in primary care coverage vis-à-vis the reentry population.

As for accessibility to health care resources, we developed measures of potential access based on capacity, demand, and distance. Capacity was measured using full-time equivalents for facilities, when available; underlying demand for services was measured as the percentage of households below the fed- eral poverty level (FPL), given that parolees are not the only populations seeking care from these facilities; and distance was measured in terms of a ten-minute travel time to facilities, assuming this population would be less mobile and more reliant on public transportation.

Table 1 shows an example of hospital accessibility for Los Angeles County. Overall, more than half the parolees reside in areas with the two lowest levels of accessibility to hospitals (shaded rows); there is also variation by parolees' race/ethnicity. For example, more African-American parolees live in areas with lower accessibility than Latino or white parolees. By way of comparison, Alameda County had a similar pattern, but in Kern and San Diego counties, more Latino parolees resided in areas with lower accessibility to hospitals than white and African-American parolees (not shown). 
Table 1. Variation in Accessibility to General Acute Care Hospitals: Distribution of Parolees Across Accessibility Levels (Los Angeles County)

\begin{tabular}{|c|c|c|c|c|}
\hline $\begin{array}{l}\text { Level of Accessibility } \\
\text { to Hospitals }\end{array}$ & $\begin{array}{c}\text { All Parolees } \\
(n=35,710)\end{array}$ & $\begin{array}{c}\text { African-American } \\
\text { Parolees } \\
(\mathbf{n}=\mathbf{1 2 , 8 8 5 )}\end{array}$ & $\begin{array}{l}\text { Latino Parolees } \\
\qquad(n=14,921)\end{array}$ & $\begin{array}{l}\text { White Parolees } \\
\quad(n=6,671)\end{array}$ \\
\hline Lowest Accessibility & 24 & 29 & 21 & 24 \\
\hline Mid-Low Accessibility & 29 & 31 & 30 & 23 \\
\hline Mid-High Accessibility & 30 & 25 & 33 & 30 \\
\hline Highest Accessibility & 17 & 15 & 16 & 23 \\
\hline Total (\%) & 100 & 100 & 100 & 100 \\
\hline
\end{tabular}

In terms of accessibility to mental health care resources across the four counties, a larger share of parolees in Alameda and Los Angeles counties returned to areas with lower levels of accessibility to mental health resources than parolees in Kern or San Diego counties. In terms of accessibility to alcohol and drug treatment providers, we see a similar pattern. About 40 percent of parolees in Alameda and Los Angeles counties resided in areas with low levels of accessibility to alcohol and drug treatment providers, compared with about a third of parolees in Kern and San Diego counties.

Although separate networks exist that provide mental health care and drug and alcohol treatment services to the parolee population, both networks have very limited capacity, suggesting that most of the reentry population must rely instead on counties' safety-net resources.

Our analysis of the health care safety net was conducted in 2009, just prior to the deep cuts made in rehabilitative programming for prisoners and in health care safety-net services in California. As of late 2011, the safety net has been stretched even thinner by budget cuts. For example, the California Department of Corrections and Rehabilitation (CDCR) has reduced funding for rehabilitative services by 40 percent, including cuts made to in-prison substance abuse programs and community-based alcohol and drug treatment programs for ex-prisoners. Although treatment providers contracted under California's Substance Abuse and Crime Prevention Act (also known as Proposition 36) appear to be a viable source of care for the reentry population, local counties are no longer funding these providers. Beginning in October 2011, Proposition 36 became instead a fee-based, participantself-pay counseling program.

\section{What Can California Do to Better Prepare for Public Safety Realignment and Health Care Reform?}

Along with the ongoing financial crisis, California's new Public Safety Realignment Plan and federal health care reform are affecting how the state and counties deal with the public health needs of returning prisoners. In 2005, California's prison medical system was put under a courtappointed federal receiver charged with bringing the level of medical care in California prisons up to a standard that no longer violates the U.S. Constitution. On May 23, 2011, the U.S. Supreme Court held that medical and mental health care for inmates still fell below a constitutional standard of care and that the only way to meet these constitutional requirements was to further reduce the size of the prison population. Public safety realignment will help close the revolving door of low-level offenders cycling in and out of prison and will help reduce the size of the prison population, returning more ex-prisoners to their communities.

As for health care reform, the ACA's expansion of Medicaid eligibility to include all non-Medicare-eligible citizens and legal residents under age 65 with incomes up to 133 percent of the FPL will allow many ex-prisoners and other individuals involved in the criminal justice (CJ) system to become eligible for health insurance under Medi-Cal (California's Medicaid program). Also, Medicaid will be expanded to more fully cover drug treatment, prevention services, and wellness programs-services particularly important for the reentry population-and create opportunities to put in place key elements of health care delivery systems (e.g., health homes, case management, patient navigators) needed to effectively manage ex-prisoners' care. Combined, these changes create a critical opportunity for California to improve access to care for the reentry population.

Importantly, public safety realignment and health care reform have a similar set of stakeholders involved in planning for these policy changes. More specifically, as part of realignment, CDRC and the counties must coordinate on transitioning responsibility for low-level offenders, while for health care reform, California's Department of Health and Human Services must coordinate with the counties on developing service delivery strategies, for example, for Medicaid expansion. This means that both policies will require the state and counties to assess capacity and build or 
enhance existing integrated service delivery systems, which requires a similar set of stakeholders. Coordination is key; otherwise, California may end up with 58 separate, countylevel implementation experiments.

The two policies also present opportunities and challenges for dealing with the reentry population. For example, realignment provides the opportunity to reduce the size of the state's prison population and the state's high parole revocation rates and focuses attention on the need to improve prerelease planning, build better mechanisms to transition care from correctional health to safety-net providers, and create or enhance existing local partnerships among probation, law enforcement, county agencies, and community- and faithbased organizations to better serve the needs of ex-prisoners returning to communities. Realignment will also enable lowlevel offenders to serve their time closer to home, thus giving them better access to family members, employers, and community organizations, which can possibly aid them with the reentry process.

But realignment will also present challenges; specifically, the traditional mechanisms for linking ex-prisoners to health care and social services (e.g., parole officers) will change dramatically for individuals placed on county-level post-release community supervision and for low-level offenders who will serve their time in county jail. Also, for low-level offenders who serve their sentence within county jail systems, a key concern is that many of these systems have little or limited rehabilitative programming. Finally, counties are concerned about their capacity to meet increased demand for mental health and drug treatment - a number of low-level offenders to be housed and monitored at the county level are expected to include individuals convicted of drug-related offenses, some proportion of whom will require treatment programs.

Similarly, the ACA will expand Medicaid, opening up the possibility for many ex-prisoners and other individuals involved with the CJ system to become eligible for Medicaid (Medi-Cal in California) and to have drug treatment services, prevention services, and wellness programs more fully covered. But there are also some challenges. For example, expansion of Medicaid eligibility could lead to increased demand for health care safety-net services that are already stretched thin, thus possibly affecting access to care if provider capacity at the county level is not increased. Also, although treatment for substance abuse problems will be more fully covered, there could be substantial cost-sharing or other utilization limits that may make it difficult for some of the reentry/CJ population to afford this care.

In that light, the study offers a series of recommendations (Table 2), which can be acted on at both the state and county levels and are based on a combination of our review of the literature and analyses of the inmate survey, parolee data, data on the health care safety net in four counties, provider interviews, and focus group discussions with formerly incarcerated men and family members.

\section{Concluding Thoughts}

We began our study with the premise that much of the reentry population eventually will become part of the uninsured and medically indigent populations in counties. This is even more the case today. Specifically, when we completed our initial analysis of the capacity of the health care safety net to meet the needs of the reentry population, we concluded that the safety net was sparse in some services and that ex-prisoners' potential access to health care services varied by county, type of service, and race/ethnicity. Given the ongoing financial crisis, the capacity of the health care safety net has shrunk substantially over time because of state and county budget cuts, while the demand for services has increased because of growth in the number of uninsured or underinsured persons. Also, within the state prison system, rehabilitative services, including substance abuse programming, have been substantially reduced. This means that the reentry population will have greater unmet needs and will have to be even more self-determined than previously, because transition points and linkages to care will become even more difficult to navigate.

While public safety realignment and federal health care reform pose some substantial challenges, they also offer unprecedented opportunities to address the needs of the reentry population by improving rehabilitative services at the local level and by improving access to health care for the reentry population (and other components of the CJ population) through Medi-Cal and other coverage expansions. Implementing both policies in ways that help serve the needs of the reentry population will require the state and counties to closely coordinate to leverage these opportunities and meet these challenges.

Both realignment and federal health reform come with funding streams to help support putting needed services into place. Realignment legislation includes initial funding for counties to implement the plan, while federal grants are available to help support states' planning of health care reform, including expanding Medicaid and developing the workforce to provide services.

Investments in planning for health care reform should be leveraged for the reentry population, for example, to develop health homes or case management systems. Doing so makes sense, because investing in treatment for this population now can help offset recidivism and other CJ costs later; moreover, expanding access to primary care and to health homes can help avoid expensive and resource-intensive care for this population. 


\section{What Can California Do to Prepare?}

Develop informed estimates about the percentage of the Medicaid expansion population that the reentry and criminal justice population will represent. There is a need for more informed estimates of the size of the reentry/CJ population that will be eligible for Medicaid and of the likely impact of different enrollment strategies.

Develop Medicaid enrollment strategies. The participation of the reentry/CJ population in Medicaid will largely depend on how much state departments of corrections and county probation and jails facilitate enrollment in Medicaid, as well as other stakeholders. California may want to consider developing strategies to enroll or reinstate Medicaid benefits for the reentry/CJ population.

Leverage the experience of other states that have previously expanded coverage to childless adults under Medicaid. Research on other states that expanded Medicaid coverage provides a rich source of information on issues and analyses California may want to undertake (e.g., effectiveness of different outreach efforts and enrollment practices on participation rates) to understand the impact of insurance expansion for the reentry/CJ population.

Develop health homes for the reentry/CJ population. The Medicaid expansion population (including the reentry/CJ component) is expected to include individuals with multiple comorbidities and high rates of mental illness and substance abuse, suggesting that health homes will be an important way to manage their complex care needs.

Develop care/case management systems that can account for special populations' needs, including those of the reentry/CJ population. California may want to consider applying for planning grants to support the development of tailored care/case management programs that will include coordination with social services and community organizations that serve special populations, including the reentry/CJ population.

Assess workforce-development strategies for alcohol, drug, and mental health treatment. Given that alcohol and drug problems and high mental health care treatment needs may overwhelm existing publicly funded treatment provider networks in the face of Medicaid expansion and public safety realignment, California may wish to establish a health task force to identify workforce-development strategies that will help build treatment provider capacity in general, and specifically to meet the expected increase in demand for services by the reentry/CJ population.

Consider developing electronic medical records. Electronic medical records are one tool for improving the transition of care from prison to safety-net providers; as such, California may wish to consider developing a pilot study to assess the feasibility of developing such records for the reentry/CJ population.

Consider expanding prerelease planning efforts. CDCR's prerelease planning for prisoners with medical or mental health conditions is based on acuity and need; CDCR and counties may want to consider expanding prerelease planning to include those with chronic medical and mental health and substance abuse problems in general.

Comprehensively assess the impact of public safety realignment to inform future policy refinements. California's 2011 Public Safety Realignment Plan represents a profound change to the state's CJ system. The legislature may wish to consider allocating funding to comprehensively assess the impact of public safety realignment and require counties to track a standard set of metrics to enable crosscounty comparisons and facilitate an assessment of the plan's overall impact.

\section{What Can Counties and Providers Do to Prepare?}

Develop county-level estimates to inform planning for rehabilitative services and for increased demand for mental health and alcohol and drug treatment. Given the growing need for mental health and alcohol and drug treatment services, county departments of mental health and alcohol and drug treatment and safety-net providers will need more informed estimates of the number of individuals who will make up the reentry/CJ population at the local level and of their expected demand for services.

Convene all relevant stakeholders for planning and coordination of services. As counties refine their plans for public safety realignment and health care reform, they may want to consider broadening the group of stakeholders to include community-and faith-based organizations that have long been involved in serving the reentry/CJ population.

Assess local capacity to meet new demands for health care. Given the important role of local public health departments and agencies, counties might wish to consider drawing on them in assessing local capacity for care, especially for those communities particularly affected by reentry and public safety realignment, and in developing strategies for addressing service gaps for the reentry/CJ population.

Develop "welcome home" guidebooks tailored to individual counties, particularly for counties and communities with high rates of return. Counties can use public safety realignment as a chance to improve and update these guidebooks to include problem-solving strategieshighlighting services that address immediate needs (e.g., housing, transportation, health care) and providing detailed information about local resources, especially about organizations committed to serving this population.

Train providers on cultural competence. Counties may want to implement provider training to improve their cultural competence, especially in primary care/public health clinics and in other settings where the primary care and specialty care needs of the reentry/CJ population will be addressed. Also, counties might consider working with community-based and faith-based organizations to ensure this training includes the perspective of the formerly incarcerated.

Consider the role of patient navigators. Being able to navigate the maze of needed services is critical. Staff who are experienced in working with this population or who have been formerly incarcerated themselves are particularly well-suited to fulfill this role. Counties might want to undertake a demonstration project to explore the use of patient navigators, particularly in counties with large reentry populations.

Address the needs of families and those who care for children of incarcerated parents. Given the importance of families to the successful reintegration of those returning from prison and the challenges the families face, there is a need for programs to address the needs of children of incarcerated parents, the needs of caregivers (e.g., respite care), and the family reunification process. Also, to inform planning decisions, counties will need better estimates of the number of children with incarcerated parents. 


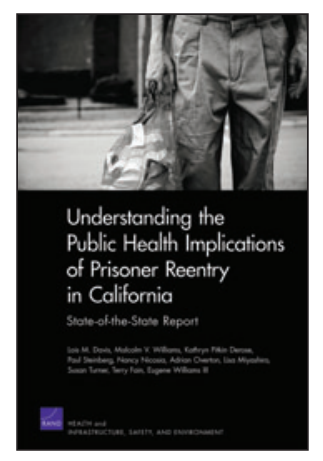

This research highlight was written by Paul Steinberg. The RAND Corporation is a nonprofit institution that helps improve policy and decisionmaking through research and analysis. RAND's publications do not necessarily reflect the opinions of its research clients and sponsors. RAND ${ }^{\circledR}$ is a registered trademark.

\section{RAND Offices}

Santa Monica, CA • Washington, DC • Pittsburgh, PA • New Orleans, LA/Jackson, MS • Boston, MA • Doha, QA • Abu Dhabi, AE • Cambridge, UK $\bullet$ Brussels, BE 


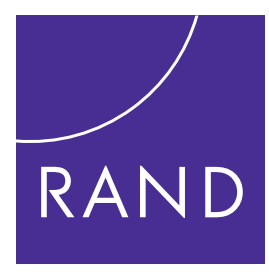

HEALTH and INFRASTRUCTURE, SAFETY, AND ENVIRONMENT
CHILDREN AND FAMILIES

EDUCATION AND THE ARTS

ENERGY AND ENVIRONMENT

HEALTH AND HEALTH CARE

INFRASTRUCTURE AND

TRANSPORTATION

INTERNATIONAL AFFAIRS

LAW AND BUSINESS

NATIONAL SECURITY

POPULATION AND AGING

PUBLIC SAFETY

SCIENCE AND TECHNOLOGY

TERRORISM AND HOMELAND SECURITY
The RAND Corporation is a nonprofit institution that helps improve policy and decisionmaking through research and analysis.

This electronic document was made available from www.rand.org as a public service of the RAND Corporation.

\section{Support RAND}

Browse Reports \& Bookstore

Make a charitable contribution

\section{For More Information}

Visit RAND at www.rand.org

Explore RAND Health

RAND Infrastructure, Safety, and Environment

View document details

\section{Research Brief}

This product is part of the RAND Corporation research brief series. RAND research briefs present policy-oriented summaries of individual published, peer-reviewed documents or of a body of published work.

\section{Limited Electronic Distribution Rights}

This document and trademark(s) contained herein are protected by law as indicated in a notice appearing later in this work. This electronic representation of RAND intellectual property is provided for noncommercial use only. Unauthorized posting of RAND electronic documents to a non-RAND website is prohibited. RAND electronic documents are protected under copyright law. Permission is required from RAND to reproduce, or reuse in another form, any of our research documents for commercial use. For information on reprint and linking permissions, please see RAND Permissions. 